\title{
VIEJOS ACTORES \\ PARA UNA HISTORIA NUEVA
}

\author{
Pilar Gonzalbo Aizpuru \\ El Colegio de México
}

$\mathrm{Pr}$ ronto se cumplirán 100 años de la inolvidable llamada que, desde Francia, pidió a los historiadores hacer una nueva historia. Su éxito puede medirse tanto en lo que realmente se ha renovado como en lo que sobre el tema se ha discutido. Como tenía que suceder, el anuncio y aun la intención de ofrecer alguna novedad han envejecido al cabo de más de medio siglo. Hoy, hasta en las publicaciones de carácter más conservador y en los textos de autores sólidamente apegados a la historia tradicional se encuentran temas, problemas y métodos que podemos identificar como propios de una nueva historia, y que, sin embargo, no parecen tener relación con los que se anunciaban antes de la segunda guerra mundial. Ante un mundo cambiante a ritmo acelerado, ya no esperamos que la historia nos anuncie el futuro mediante la explicación del pasado, ni siquiera parece que nos haga entender el presente. Como una forma de explicación de viejos acontecimientos y como proyecto de interpretación de cambios permanentes de la sociedad, la historia del último cuarto del siglo xx y sus inicios del xxI muestra un justificado desaliento y un oscilante 
cambio de rumbo. ${ }^{1}$ Pero ni la inmovilidad ni la vuelta atrás serían deseables. Así como los acontecimientos cambian de ritmo y los problemas modifican su contenido, la historia ha cambiado a lo largo de los siglos.

El gran cambio, en el siglo XIX, correspondió a Marx, con la introducción en la historia de las clases sociales, comunidades de presencia e influencia indiscutibles, que abrieron la puerta a otras posibles configuraciones, de modo que, en la actualidad, todo científico social, y todo historiador, imagina sujetos colectivos. En la segunda mitad del siglo XIX ya las clases sociales habían ganado un lugar que, a lo largo del xx, fue con frecuencia desplazado por el eufemismo de "la sociedad". Esa ambigua y multifacética sociedad fue complementada y en ocasiones sustituida en la Nueva Historia por las peculiares configuraciones que ubicaron como protagonistas a grupos étnicos, económicos, culturales, religiosos... hasta, una vez más, fragmentar el número de esos actores colectivos que deberían representar al pueblo, la plebe, las masas o, en definitiva, los individuos anónimos que, sin saberlo, hicieron la historia.

Así, sustituidas las personalidades por el grupo, y la masa amorfa por el colectivo, con intereses y características peculiares, la historia de las últimas décadas, ya sin las pretensiones de novedad, pero comprometida con el presente, reconoció en los grupos y comunidades a los héroes y a los villanos, a quienes he buscado en los artículos publicados desde 1992 en Historia Mexicana, la revista del Centro de Estudios Históricos de El Colegio de México. No pretendo que sean grupos recién nacidos, al calor de la modernidad; teóricamente integrados en grupos verdaderos, ya sea en nuestro mundo o en el pasado, todos los colectivos son imaginarios: resultan de un proceso

1 Sin extenderme en cuestiones teóricas, es oportuno mencionar los artículos de François Hartog, Saurabh Dube y José Enrique Ruiz-Doménec, en Guillermo Zermeño (ed.), Historia/Fin de siglo, México, El Colegio de México, 2016. 
de abstracción que escoge un rasgo y lo convierte en definición. Algunas veces son los propios sujetos los que creen en la existencia de ese colectivo imaginario y piensan, por poner un ejemplo, que existe tal cosa como "los europeos", e incluso se sienten "europeos", aunque estén dispuestos a quemar sus pasaportes en cuanto estén en juego sus ventajas económicas o se discuta su particular superioridad. Pasando a otro ejemplo: lo que se llamaba el "espíritu de cuerpo" era frecuente en las milicias, en algunas órdenes religiosas y en grupos paramilitares, como pudieron considerarse desde los legionarios romanos hasta los fascistas en sus centurias. Igualmente podría recordar a Los mandarines ${ }^{2}$ o a los intelectuales de nuestro siglo. Otras veces, esos colectivos son imaginados por alguien, con algún propósito, así como los nazis inventaron a "los judíos" con las leyes de Nüremberg (que estipularon que era judío aquel que tuviese al menos un abuelo judío, aunque fuesen conversos de diez generaciones).

No es irrelevante que esos colectivos imaginados por los científicos sociales no hubiesen sido ni siquiera inteligibles para los sujetos a los que se refieren (mujeres abandonadas en el siglo xix, afrodescendientes en el siglo xvIII, por ejemplo). Inventados por motivos políticos o por conveniencia de un proyecto académico, una vez creado el grupo sólo hay que encontrar sus semejanzas y peculiaridades. Ya decididos a formar grupos, los indigentes pudieron cargarse con todos los estigmas de la pobreza, los empresarios oscilarían entre la representación del capitalismo despiadado de la modernidad y los vestigios de la explotación clasista del viejo orden, los extranjeros, en cualquier momento del pasado, eran potencialmente capaces de convertirse en enemigos del país que los acogía y, por lo tanto, según las circunstancias, igualmente aptos para ser tratados como un colectivo amenazador o amenazado, peligroso o perseguido. Las mujeres,

${ }^{2}$ La ejemplar configuración de grupo en la obra de Simone de Beauvoir. 
en cualquier actividad pública seleccionada, son candidatas a formar no uno sino diversos grupos de estudio.

\section{LOS ACTORES DE SIEMPRE}

Entre los cientos de artículos publicados durante las últimas tres décadas en Historia Mexicana, hay algunos protagonistas peculiares, que asoman sus múltiples caras desde diferentes perspectivas. Considero, en primer lugar, a los indios, como esa identidad abstracta construida a partir del siglo xvI, o como actores colectivos en grupos con demandas específicas o actividades compartidas. Puedo referirme a varios textos que ofrecen nuevas miradas y aproximaciones a una comprensión de cuanto los aborígenes americanos han aportado y siguen aportando a los problemas y quizá a las soluciones de las naciones y regiones orgullosamente modernas.

La creación de la categoría de indios no es en absoluto algo nuevo; fue una improvisación práctica adoptada por la burocracia colonial, todavía inspirada por la creencia colombina de que había llegado a la India. Así que, simplificando, la corona y sus funcionarios optaron por designar como indios a todos los nuevos vasallos de ese continente que se dividiría en virreinatos, pero que genéricamente se designaba como "las Indias". Indianos eran también los españoles que regresaban a España, enriquecidos o no, tras una estancia en las provincias de Ultramar que ya habían recibido, por reconocimiento internacional, el nombre de América. No se aprecia contradicción en los textos antiguos y modernos relativos al "indio" o su representación en contraste con el criollo o el mestizo. Pero la precisión en el lenguaje nos obliga a repensar en el contenido real de la categoría de indio que se asignó a todos los aborígenes del continente, de norte a sur y de este a oeste, cuando tantas y tan profundas diferencias se fueron descubriendo en su origen y desarrollo a lo largo de los siglos, hasta el momento actual, en que el concepto indio 
corresponde a poblaciones muy diferentes en los países del continente americano, con un contenido más político y social que étnico y tradicional. Para no incurrir en generalidades insostenibles, Florencia Mallon recomendaba hace casi dos décadas no convertir lo indígena en estereotipo para promoción turística sino en fundamento de la cultura popular. ${ }^{3}$ Por supuesto, esta observación implica el reconocimiento de que el indio del siglo XXI ha cambiado profundamente del que fue siglos atrás.

Durante el virreinato, el tribunal eclesiástico del arzobispado de México asumió las responsabilidades judiciales que le correspondían, en cuanto a las causas relacionadas con la fe y las costumbres de los naturales. Según señala Jorge Traslosheros, por tratarse de los recientemente conversos, no estuvieron sujetos al Santo Oficio de la Inquisición desde su instalación en el virreinato, en 1571, y tampoco hay noticia de que el Tribunal realizase verdaderas campañas de extirpación de herejías, pese a las denuncias conocidas a lo largo del siglo xvir. Para los clérigos legistas, que atendieron la que comúnmente se llamaba Audiencia arzobispal, no hubo la menor duda acerca de su jurisdicción sobre los indios de la arquidiócesis, cualquiera que fuera su grupo étnico o su lugar de residencia. No sólo se trataba de una vieja historia compartida, sino de una realidad permanente de poblaciones sumidas en la ignorancia de la fe y en riesgo de caer en prácticas de hechicería y supersticiones. ${ }^{4} \mathrm{El}$ silencio sobre muchos levantamientos indígenas durante la colonia no significa que no los hubiera, sino que se aplastaron y se silenciaron. En los inicios del siglo xIx los movimientos indigenistas tuvieron su presencia en los proceso de independencia de los países hispanoamericanos,${ }^{5}$ sin que desapareciera la distancia entre el

3 Mallon, “Entre la utopía y la marginalidad” (166), 1992, pp. 473-504.

4 Traslosheros, "El tribunal eclesiástico y los indios" (203), 2002, pp. 485516.

5 KöNIG, "El indigenismo criollo” (184), 1997, pp. 745-767. 
indio ideal, al que habría que conservar en su pureza, y los indios verdaderos, que exigían derechos y reivindicaciones.

Un intermedio pintoresco en la relación de los indios con el poder político, así como con el hipotético campo teórico que los agrupaba, se dio durante el efímero imperio de Maximiliano, que, deslumbrado por el exotismo de sus nuevos vasallos, se acercó a ellos, con la mirada romántica que los comparaba con los novelescos mohicanos de Fenimore Cooper. Con espíritu paternalista, procuró atender sus demandas y encontró en ellos la confianza y lealtad que no podía darle el resto de la población. ${ }^{6}$ Esa imagen abstracta e idealizada del indio inocente, apegado a la naturaleza, austero en sus necesidades y ajeno a las novedades, no se sostenía en las duras circunstancias provocadas por el ineludible avance de la modernidad, empujado por las necesidades de la mayoría y la ambición de unos cuantos. Desde las bien intencionadas advertencias de los primeros evangelizadores hasta los movimientos radicales de los siglos Xx y xxi, la cultura indígena o la integración-marginación de los indios han influido de algún modo en los cambios sociales o políticos que pretenden hacer justicia a poblaciones secularmente subyugadas, aunque los resultados no siempre sean satisfactorios. La cuestión, que en varios volúmenes de Historia Mexicana se destaca, es que el imaginario conjunto indios, o su interpretación en la convención que el término expresaba, ha cambiado en su realidad tanto como en la interpretación de los historiadores. Algo diferentes son los estudios sobre comunidades concretas, que actuaron como tales, en protestas contra abusos de encomenderos, párrocos o gobernadores, en defensa de tierras y privilegios o como actores económicos en la promoción de actividades productivas. ${ }^{7}$ Algo que también se aprecia en las

6 PANi, “¿Verdaderas figuras de Cooper?” (187), 1998, pp. 571-604.

7 Garavaglia y Grosso, “Indios, campesinos y mercado” (182), 1996, pp. 245-278; CASO, “Organización política” (204), 2002, pp. 713-748; EscOBAR Ohmstede, “Indígenas y comercio” (218), 2005, pp. 333-417; CÁRdenas, “Lo 
lecturas es que en el ámbito académico de las últimas décadas se ha pretendido deslindar el contenido de términos como indios, aborígenes, naturales, indígenas, que no deberían usarse como sinónimos porque corresponden a realidades distintas. ${ }^{8}$

\section{OTROS VIEJOS ACTORES}

En todas las sociedades se han reconocido grupos prominentes por su linaje, poder político, riqueza e influencia en las costumbres. Con frecuencia, pero no siempre, han coincidido todos los caminos de ascenso a esa influencia aceptada dentro de una región. No me refiero a las instituciones religiosas, que merecen un estudio aparte, ni a caudillos guerreros que ganaron su prestigio en circunstancias extraordinarias. En momentos críticos de la historia de México se destaca la preeminencia de quienes, al margen de cargos públicos o desde ellos, pero con una clientela más personal que oficial, fueron secundados en sus decisiones. Grupos de criollos poderosos en las ciudades novohispanas influyeron en la respuesta de esas ciudades a los primeros levantamientos por la independencia. Juan Ortiz muestra la capacidad de arrastre de la población por parte de eminentes criollos afines a la insurgencia en lugares como Guadalajara, Zacatecas, Celaya y Valladolid, frente a Guanajuato, Querétaro, Puebla o Veracruz, bajo autoridades con fuerte poder a favor de los realistas. Las decisiones de los grupos dominantes señalaron las posiciones en los inicios de la contienda. ${ }^{9}$ Desde cargos burocráticos, con ambiciosas estrategias matrimoniales y acuerdos económicos con vecinos comprometidos en intereses comunes,

que queremos es que salgan" (264), 2017, pp. 1863-1921; LIRA, “De buenos mexicanos” (275), 2020, pp. 1091-1142.

8 Así lo han visto González Undurraga, “De casta a la raza” (239), 2011, pp. 1491-1525, y Ramírez Zavala, “Indio/indígena, 1750-1850” (239), 2011, pp. 1643-1681.

9 Ortiz Escamilla, “Las élites de las capitales” (182), 1996, pp. 323-357. 
algunos individuos lograron formar sus propias redes de influencia, con capacidad para controlar la política y la economía de su territorio. ${ }^{10}$

Por su parte, los aristócratas de la Nueva España fueron representantes del sentimiento de pertenencia a un grupo privilegiado, por razones de nacimiento y posesión de bienes, y a menudo prestigiado por un ilustre antecesor. Aun obligados a prescindir de títulos nobiliarios, tras el decreto republicano de extinción, las respuestas oscilaron entre el abandono de México, por salvar los privilegios, o los intentos de adaptación, caracterizados por el empeño en recuperar dentro del nuevo orden la posición de superioridad que la sangre ya no les garantizaba. Verónica Zárate destaca los esfuerzos de varios exnobles por conservar un reconocimiento entre las dignidades de la república. ${ }^{11}$ Los lugares vacantes en la cúspide de la sociedad por la caída en desgracia de los nobles fueron ocupados por una nueva élite, de grupos y familias distinguidos por la riqueza. Ya en el siglo XIX y al margen de enfrentamientos políticos y militares, Mario Cerutti se refiere a un grupo de emigrantes españoles, de las regiones del norte: vascos, asturianos y montañeses (santanderinos), jóvenes, emprendedores y hábiles, que con el respaldo de sus paisanos lograron formar, en la región de La Laguna, una poderosa red de actividades agrícolas, ganaderas, mineras, industriales y mercantiles, con las cuales transformaron radicalmente la economía de la región e influyeron en la prosperidad nacional. El grupo se consolidó a lo largo de varias generaciones. ${ }^{12}$

Con similitudes aparentes, pero diferencias esenciales, la categoría de extranjeros ha sido usual a lo largo del siglo xx y así lo reflejan los artículos de nuestra revista. Sin embargo, no se trata

10 Alcántara, “Elites ganaderas” (223), 2007, pp. 779-816.

11 Zárate, "El destino de la nobleza” (260), 2016, pp. 1789-1815.

12 Cerutti, "Propietarios y empresarios" (192), 1999, pp. 825-870. 
de un término que corresponda a quienes comparten caracteres comunes, sino sólo la negación de algo que no comparten, la nacionalidad mexicana, pese a vivir en México. No fueron los académicos sino los burócratas quienes imaginaron este grupo, que se consideraba como tal desde hace más de tres siglos. Con esta reserva, los menciono para recuperar interesantes aportaciones de varios textos. Hoy parece sorprendente que en algún momento se buscara establecer colonias de migrantes en la región del actual estado norteamericano de Texas, que en el siglo xviII constituía los confines septentrionales del virreinato de la Nueva España, tan lejos del centro que de continuo sufría la amenaza de invasión de tribus indias o los intentos de ocupación de los vecinos países colonizadores. El intento de atraer católicos irlandeses no dio el resultado que se esperaba de ellos. ${ }^{13}$

Entre los extranjeros en la República mexicana, los españoles constituyeron un caso especial, porque las redes creadas a ambos lados del Atlántico, a lo largo de 300 años, no podían romperse con decretos y ordenanzas. Por una parte, persistía el rencor alentado durante los años de insurgencia contra los indeseables gachupines y por otro se enfrentaba el fracaso en los intentos de rechazarlos, una y otra vez. La tolerancia predominó en general, pero los viejos resentimientos cobraron vigor en los años de la revolución, cuando la expulsión de extranjeros en general y españoles en particular alcanzó cifras sin precedentes. ${ }^{14}$ Los estadounidenses sufrieron similar suerte a lo largo del siglo XIX, cuando se consideraron maleantes que huían de la justicia de su país. ${ }^{15}$ Como señala Erika Pani, no abunda la bibliografía sobre el tema de los extranjeros y su impacto en la vida nacional, pese a que en ocasiones se ha sobreestimado su influencia sobre la economía, las costumbres y las modas. La escasez de estudios se

13 Alanís Enciso, “Los extranjeros” (179), 1996, pp. 539-566.

14 Landavazo, "Para una historia social” (233), 2009, pp. 195-225; YANKELEVICH, “Extranjeros indeseables” (211), 2004, pp. 693-744.

15 Yankelevich, "Explotadores, truhanes” (228), 2008, pp. 1155-1199. 
justifica al considerar que, en el México decimonónico, de 1821 a 1910, su presencia en el país no alcanzó el 1\% de la población. En el mismo periodo, el número de mexicanos en Estados Unidos duplicaba el del total de extranjeros en México. ${ }^{16}$

Siempre se han encontrado en la sociedad algunas minorías identificadas como tales por los mismos componentes y por los demás. Fueron, desde tiempos remotos, los practicantes de algunas sectas religiosas, los pertenecientes a grupos étnicos aislados, los enfermos de ciertas enfermedades como la lepra, o los supervivientes de pueblos conquistados, reducidos en número y disminuidos en derechos, como los barrios de juderías y morerías en la península ibérica medieval y de la modernidad temprana. Los judíos han sido un grupo definido por sus propias creencias y costumbres, pero, sobre todo, por la actitud de los demás hacia ellos. Hablar de judíos en la Nueva España es tanto como referirse a la Inquisición, pero ya en el México independiente y a mediados del siglo xx, la política del gobierno mexicano osciló entre la aceptación y el rechazo, ante las teorías racistas que incluían el antisemitismo, contra el que tuvieron que defenderse y que impulsó la formación del Comité Mexicano contra el Racismo (CMR), en relación con el comité Judío Americano (AJC). ${ }^{17}$

Los chinos constituyeron otro caso particular, ya en las primeras décadas del siglo xx. Su particularidad estriba en que verdaderamente formaron un grupo de actores sociales, en gran medida cohesionados y voluntariamente distanciados, con impacto económico en la región en que se establecieron, $\mathrm{y}$ de quienes puede considerarse que cerraron un ciclo desde su llegada hasta su dramático final, expulsados y masacrados. ${ }^{18}$

\footnotetext{
16 PAni, "Ciudadanos precarios” (246), 2012, pp. 627-674.

17 Gleizer, “De la apertura al cierre” (238), 2010, pp. 1175-1227; KATz GuGENHEIM, “Las relaciones entre los judíos” (246), 2012, pp. 795-858.

18 Velázquez Morales, “Diferencias políticas” (218), 2005, pp. 461-512.
} 


\section{LOS NUEVOS ACTORES}

No ignoro que en el momento en que decido seleccionar determinados conjuntos o convenciones, estoy definiendo determinadas categorías, y eso es, precisamente, lo que hacemos los historiadores cuando delimitamos nuestro objeto de estudio. De ahí que la mirada a los colectivos estudiados en cualquier época elegida corresponda a las inquietudes de esa historia que hoy, en el siglo xxI, oscila entre lo global y lo fragmentado, la fracasada modernidad y la angustiante mirada al futuro. El problema conceptual interesante es que esos colectivos imaginados inevitablemente borran diferencias reales entre los individuos, pero también revelan cosas sobre ellos: importa saber si realmente ayudan a conocer más y mejor, si aprendemos algo de ellos al verlos como parte de un colectivo, o resulta que es más lo que perdemos al reducirlos. En concreto, como ejercicio práctico: ¿qué nos han enseñado los colaboradores de Historia Mexicana acerca de esos sujetos imaginarios?

Me ha sorprendido encontrar pocos trabajos destinados a las mujeres. Me consta que están presentes en otros espacios, libros personales y capítulos de libros colectivos. Las que asoman a las páginas de la revista lo hacen desde los extremos de la transgresión de las leyes o el camino a la santidad. La venerada maternidad, ensalzada por la política y la religión, ha sido durante milenios el eslabón indestructible en la cadena de la sumisión femenina. En las páginas de un número reciente de la revista, encuentro una mirada desapasionada, que se aleja de los gozos de la maternidad para mostrar los tormentos de la pobreza, la violación, la vergüenza, el abandono, y, como solución extrema, el aborto prohibido por la ley, el infanticidio, el robo y la ruina moral y material. ${ }^{19}$ En contraste, las "Señoras de la Caridad", damas virtuosas, preocupadas por la salvación de las almas que

19 SAntillán, “Maternidad y transgresiones” (271), 2019, pp. 1121-1164. 
pretenden rescatar dedicándoles su tiempo y ofreciendo ayuda material a cambio de la conversión pasajera o permanente de las familias beneficiadas con limosnas. ${ }^{20} \mathrm{Y}$, en el extremo de la fe y el atrevimiento, las mujeres que durante la Guerra Cristera asumieron los riesgos de esconder a los eclesiásticos, salvar las imágenes y llevar consigo la eucaristía a los creyentes enfermos y moribundos, cuando los sacerdotes eran perseguidos. Ellas arriesgaron sus propias vidas y la seguridad de sus familias, convencidas de que ganaban el paraíso y orgullosas de compartir las tareas sagradas del sacerdocio, inalcanzables en condiciones normales. ${ }^{21}$ Con una visión más amplia y actualizada, el artículo "De la mujer moderna a la mujer liberada" analiza, a partir de la mirada a dos décadas de la revista Clandia, el viraje desde los años sesenta a los setenta, al enfrentar los prejuicios de lo femenino con las exigencias de la modernidad. Con moderación, cautelosamente, en Claudia el feminismo daba a conocer sus primeros balbuceos y lo "moderno" no se limitaba a modas y peinados, sino que prometía apertura y reconocía capacidad de decisión en actividades laborales, académicas, familiares, sociales, recreativas... y en el delicado terreno de la maternidad voluntaria y programada. ${ }^{22}$

Los mendigos y los delincuentes, los locos y los trabajadores callejeros encontraron su lugar en publicaciones de años recientes y eso se refleja en los textos de Historia Mexicana. Ya eran conocidas las gavillas, que alteraron el orden durante los años de inseguridad y violencia mientras luchaban realistas contra insurgentes. Quizá fueron esos “rebeldes y transgresores" los que abrieron la puerta para los doblemente marginados, de la sociedad y de la historia. ${ }^{23}$ En las últimas décadas del siglo XIX, los indigentes fueron actores que influyeron sobre la política

20 Arrom, “Las Señoras de la Caridad” (226), 2007, pp. 445-490.

21 Butler, “Su hija Inés” (267), 2018, pp. 1249-1294.

22 Felitti, “De la 'mujer moderna”" (267), 2018, pp. 1345-1394.

23 Pacheco, “Rebeldes y transgresores” (233), 2009, pp. 327-354. 
social del gobierno de Porfirio Díaz, cuando las instituciones de auxilio público constituyeron el único recurso de subsistencia para quienes ostentaban su desdicha que los acreditaba como aptos para ingresar en el Hospicio de Pobres, que disponía de 600 lugares, o en el Tecpan de Santiago (Escuela Industrial de Huérfanos), con capacidad para recibir a 250 alumnos. Los solicitantes se presentaban a sí mismos como el modelo de pobre inocente abatido por las desdichas. ${ }^{24}$ Transcurridas más de dos décadas y establecido el nuevo orden de la posrevolución, el gobierno asumió los servicios sociales con distinción de la asistencia social para pobres desvalidos y la seguridad social, que correspondía a los trabajadores..$^{25}$

En las referencias a los indigentes, los textos se centran en la pobreza urbana y, en particular, en la ciudad de México, en donde la inmigración de quienes no sólo carecían de recursos sino de habilidades para sustentarse incrementaba las proporciones de la pobreza. De ahí que, en la primera mitad del siglo xx, aumentase el número de locos asilados en el manicomio de La Castañeda y que proliferasen como nunca antes los vendedores callejeros y la oferta de servicios o exhibición de habilidades, como limpiadores de coches o equilibristas y maromeros. ${ }^{26}$

\section{PASANDO PÁGINA}

Los caminos de la novedad de ayer ya no soy los de hoy. Si hemos cambiado la forma de hacer historia es porque las técnicas, los tiempos, las expectativas y los efectos de la globalización así lo imponen. La novedad que se advierte está en las preocupaciones actuales, que parecen ser diferentes de las antiguas. No

${ }^{24}$ El artículo trata de 1877 a 1905. Lorenzo, “Los indigentes” (245), 2012, pp. 195-247.

${ }_{25}$ Lorenzo, "El análisis de la pobreza” (268), 2018, pp. 1677-1724.

${ }^{26}$ Ríos Molina, "Indigencia, migración y locura” (236), 2010, pp. 1295-1337; Barbosa, “Trabajadores en las calles” (238), 2010, pp. 1077-1118. 
todo lo nuevo es mejor que lo anterior, sino, quizá, intrínsecamente más complejo o más difícilmente comprensible; en todo caso, la novedad está por dondequiera y ya ni siquiera parece novedad porque, además, otras ciencias sociales (antropología y sociología, en particular) han aportado categorías a las que antes no se prestaba atención. Es indiscutible la apertura hacia temas efectivamente originales, antes ignorados, que se han introducido sutilmente hasta incorporarse a estudios definidos por inquietudes más relacionadas con la sólida y tradicional historia política o con la económica. ${ }^{27}$ En esta ocasión, al reflexionar sobre la aportación de "nuestra" revista al conocimiento del pasado, he buscado a los grupos reales o imaginarios que, en los últimos tiempos, se han convertido en protagonistas de la historia. Esos protagonistas, ya no como héroes solitarios sino como grupo de actores sociales, están presentes en casi todas las investigaciones, si bien en algunas se limitan al papel de víctimas o testigos impotentes de acontecimientos que los sobrepasan.

Entre los artículos publicados en las últimas décadas, he buscado los dedicados a las comunidades que lo son en función de inquietudes sociales, preocupaciones políticas y obsesiones de académicos originadas a partir de mediados del siglo xx. El movimiento feminista, el proceso de descolonización en Asia y África y, en última instancia los movimientos de liberación sexual, influyeron en la sociedad, en la política y en la academia. Con el feminismo se descubrió que había otra historia nunca antes contada: la mitad de la humanidad había quedado fuera de una historia que no le había prestado atención. Por las mismas fechas, con los movimientos de descolonización se descubrieron nuevos sujetos, que habían sido silenciados y cuya historia había sido negada. Se trataba de un silencio culpable: las mujeres y los

27 Siempre hubo historiadores particularmente sensibles, que mencionaron los temas relacionados con lo cotidiano, que se relegaban a las últimas páginas o las notas de "letra pequeña". 
pueblos de las antiguas colonias, pero, además, todos los olvidados, los marginales, los desdeñados por el orden oficial, habían sufrido el rechazo de un "imperialismo cultural" que estaba en deuda con ellos. La calidad de víctimas les daba una autoridad moral que les permitía exigir compensaciones. Para los historiadores de las últimas décadas se imponía contar la historia desde el punto de vista de esos sujetos, que se consideraban moralmente superiores, y que incluso podía sugerir un acercamiento al viejo espíritu revolucionario, ya desgastado con la vulgarización de lo que hace cien años fueron las clases sociales.

Algo de eso he encontrado y vale la pena destacarlo, en estos tiempos de modas y cambios, cuando apenas llega a fraguar un modelo, ya se está preparando el siguiente. 
